\title{
COMPLICATED LUMBAR TUBERCULOUS SPONDYLODISCITIS IN DISSEMINATED TUBERCULOSIS, TREATED USING A NON-CONVENTIONAL ANTERIOR SUPPORT SYSTEM FOR HYDROSTATIC DISTRACTION: A CASE REPORT
}

\section{TRATAMENTO DE ESPONDILODISCITE LOMBAR COMPLICADA EM TUBERCULOSE DISSEMINADA COM SISTEMA HIDROSTÁTICO DE DISTRAÇÃO LOMBAR: RELATO DE CASO}

\author{
Alex Oliveira de Araujo ${ }^{1}$, Thiago Queiroz Soares ${ }^{1}$, Alessandro Gonzalez Torelli ${ }^{1}$, Allan Hiroshi de Araujo Ono ${ }^{1}$, \\ Raphael Martus Marcon ${ }^{2}$, alexandre Fogaça Cristante ${ }^{2}$, Tarcisio Eloy Pessoa de Barros Filho ${ }^{1}$ \\ 1. Hospital das Clínicas da Faculdade de Medicina da Universidade de São Paulo (IOT-HCFMUSP), Instituto de Ortopedia e Traumatologia, Spine Surgery Division, São Paulo, SP, Brazil. \\ 2. Hospital das Clínicas da Faculdade de Medicina da Universidade de São Paulo (IOT-HCFMUSP), Instituto de Ortopedia e Traumatologia, Laboratory of Medical Investigation, Spine \\ Surgery Division, São Paulo, SP, Brazil.
}

\section{ABSTRACT}

Objective: To describe a case of disseminated tuberculosis affecting the lumbar spine that was treated using a non-conventional anterior support system. Background: Tuberculous spondylodiscitis is the most common and most severe form of extrapulmonary tuberculosis. Although antibiotic therapy is the most frequently used treatment, surgery is necessary in cases of neurological deficit, spinal instability, significant deformity, severe sepsis, paravertebral and epidural abscesses or in cases wherein clinical treatment has failed. A surgical procedure is also indicated when a biopsy is required. With the development of new methods for reconstruction and fixation of the spine, complete debridement of the tuberculous foci has become an increasingly common approach, but there is a lack consensus on the best technique. Methods and results: The patient suffered from disseminated tuberculosis affecting the lumbar region of the spine, with an abscess in the psoas muscle. He underwent extensive debridement via both anterior and posterior approaches, using a non-conventional anterior support system that promotes hydrostatic distraction. Conclusions: Treatment using the hydrostatic distraction system was able to reestablish both the stability and anatomy of the lumbar curve. Level of evidence IV, Case report.

Keywords: Spinal tuberculosis, Osteoarticular tuberculosis, Debridement, Surgical procedures.

\section{RESUMO}

Objetivo: Descrever um caso de tuberculose disseminada afetando a coluna lombar, tratada com um sistema de suporte anterior não convencional. Contexto: Espondilodiscite tuberculosa é a forma mais comum e mais grave de tuberculose extrapulmonar. Embora o principal tratamento seja a antibioticoterapia, o tratamento cirúrgico é importante em casos de déficit neurológico, instabilidade da coluna e deformidade significativa, sepse grave, abscessos paravertebrais ou peridurais ou em casos de falha do tratamento clínico. Cirurgia também é necessária quando há necessidade de biópsia. Com o desenvolvimento de novos métodos para a reconstrução e fixação da coluna, cada vez mais se faz o debridamento completo do foco da tuberculose vertebral, mas há falta de consenso sobre a melhor técnica. Métodos e Resultados: O paciente sofria de tuberculose disseminada afetando a coluna, na região lombar, com abscesso do músculo psoas. Foi tratado com extenso debridamento pelas vias anterior e posterior, usando um sistema não convencional de suporte anterior que promove distração hidrostática. Conclusões: O tratamento com o distrator hidrostático foi capaz de restabelecer a estabilidade e a anatomia da curva lombar. Nível de evidência IV, Relato de caso.

Descritores: Tuberculose da coluna Vertebral. Tuberculose osteoarticular. Desbridamento. Procedimentos cirúrgicos operatórios.

Citation: Araujo AO, Soares TQ, Torelli AG, Ono AHA, Marcon RM, Cristante AF, Barros Filho TEP. Complicated lumbar tuberculous spondylodiscitis in disseminated tuberculosis, treated using a non-conventional anterior support system for hydrostatic distraction: a case report Acta Ortop Bras. [online]. 2018;26(6):401-5. Available from URL: http://www.scielo.br/aob.

All authors declare no potential conflict of interest related to this article.

Work was conducted at the Department of Orthopaedics and Traumatology, Instituto de Ortopedia e Traumatologia, Hospital das Clínicas da Faculdade de Medicina da Universidade de São Paulo (IOT-HCFMUSP), São Paulo, Brazil.

Correspondence: Alexandre Fogaça Cristante. Rua Dr. Ovídio Pires de Matos, 333, São Paulo, Sp, Brazil. 04018-001. aacristante@gmail.com 


\section{INTRODUCTION}

Extrapulmonary tuberculosis is the result of a combination of factors, such as the type of pathogen, the host genetics, and environmental factors. Factors related to the pathogen relate to its virulence and its biological properties of dissemination. Factors related to the host are focused on the patient's immune status; the vast majority of patients who develop extrapulmonary dissemination having some type of immunodeficiency, with infection by the HIV virus and systemic lupus erythematosus being the most common. ${ }^{1}$

The incidence of extrapulmonary tuberculosis varies in different parts of the world, according to race, age, sex and comorbidities. Incidence of around 37\% is reported in Cambodia, while in China the incidence is close to $7 \%{ }^{1}$

In their meta-analysis, Webster and Shandera proposed a prototype of patients at higher risk of developing extrapulmonary tubercuIosis; young women, infected by the HIV virus, without diabetes, non-smokers and who do not use alcohol in excess. On the other hand, the typical profile of patients with pulmonary tuberculosis is more elderly males, who smoke and drink alcohol in excess, and who are generally not infected by the HIV virus. ${ }^{1}$

Among the various forms of extrapulmonary tuberculosis, tuberculous spondylodiscitis is the most serious and common form, representing around $40 \%$ to $50 \%$ of all cases of tuberculosis that affect the osteoarticular system. Its overall incidence has increased due to the increase in the phenomena of migration, malnutrition, and the rate of infection by the HIV virus. ${ }^{2-5}$

The most common treatment of vertebral complication is still antibacterial chemotherapy. However, surgical treatment plays an important role in some situations, such as in the presence of neurological deficit, significant spinal instability and deformity, severe sepsis, paravertebral and epidural abscesses, and in cases of clinical treatment failure. A surgical procedure is also needed when there is a need for biopsy. ${ }^{2,3}$

For many years, "Hong Kong" surgery (focal debridement) was the main choice for the treatment of lumbar tuberculosis. Recent studies show that incomplete debridement is the main cause of recurrence after surgery in cases of vertebral tuberculosis. The recurrence rate is around $13 \%$ to $26 \%$ in the first surgery, and can reach $6 \%$ to $23 \%$ in the second surgery. 6,7

In view of this, and with the development of new methods of reconstruction and fixation of the spine, surgeons are beginning to understand the importance of complete debridement of foci of vertebral tuberculosis. As a result, the current trend, in cases of lumbar tuberculosis complicated with abscess formation, is a broad surgical approach, with the aim of reducing this reoperation rate. ${ }^{6,8}$ The aim of this article is to report a case of disseminated tuberculosis with lumbar involvement complicated with psoas muscle abscess, which was treated by surgery with extensive debridement, by the anterior and posterior approaches, using a non-conventional anterior support system that promotes distraction through hydrostatic means, reestablishing the stability and anatomy of the lumbar curve.

\section{Case report}

Written informed consent was obtained from the patient for publication of the study.

A male patient, 35 years of age, from Bolivia, living in Brazil for five years, previously healthy, came to the basic health unit reporting a history of pneumonia for the preceding 12 months, treated for one month with oral antibiotics. Following these symptoms, he began to develop lumbar pain, with progressive worsening, associated with pain and difficulty moving the left leg, and difficulty walking. He was advised to take painkillers and perform physiotherapy exercises. He presented partial improvement of symptoms with physiotherapy; however, after two months, he developed hematuria associated with fever and vomiting, with worsening lumbar pain. He was then evaluated at a health care unit, this time with a suspected urolithiasis. During clinical investigation through laboratory tests and imaging exams, lung alteration was observed, associated with an abscess of the left psoas muscle. The patient reported weight loss of around $20 \mathrm{~kg}$ during this period. His clinical condition significantly worsened, and he was admitted for treatment and complementary examinations.

In the physical examination at hospital admission, the patient was conscious and oriented, with decreased muscle strength in the muscle groups innervated by the nerve roots of the lumbar spine $L 2$ and L3 on the left (grade 3) and L4, L5 and S1 on the left (grade 5), according to the American Spinal Injury Association Impairment Scale motor impairment scale adopted by the (ASIA), without motor or sensory deficits identified in the right leg. He had severe pain on moving the left leg. Although motor strength was partially preserved, he was unable to walk, and could not tolerate standing due to lower back pain and irradiation to the left leg.

Serologies were performed for HIV, hepatitis B and hepatitis C, all with negative results. Exams for autoimmune, immunosuppression and immunodeficiency disorders not related to HIV were also negative. Imaging exams performed on admission and during hospitalization showed:

- Complete CT of the abdomen: free liquid in the cavity, diffuse infiltration of mesenteric fat. Lesion of lithic appearance in the vertebral body of the fifth lumbar vertebra (L5), with the formation of a heterogeneous mass that has invaded the adjacent left psoas muscle and spinal canal.

- Esophagogastroduodenoscopy: esophageal-mediastinal fistula.

- CT scan of the chest with contrast: bilateral nodular pleural thickening, more voluminous on the right. Enlarged lymph nodes in the right internal mammary chain, and pleural effusion in the right lung.

- Computed tomography of the thoracic and lumbosacral spine (Figure 1): Iytic lesion of the vertebral body of the fifth lumbar vertebra, affecting the left pedicle, with enlargement of the left psoas muscle, suggestive of fluid build-up.

- MRI of the skull: imaging findings consistent with meningeal inflammatory or infectious process, predominantly frontal. Cortical change in the adjacent subcortical white matter is also highlighted, which may be related to the area of cerebritis in the left frontal lobe. It is known that these findings can be found in association with neurotuberculosis. Foci of restriction to the dissemination of water molecules adjacent to the above-mentioned inflammatory or infectious process, compatible with acute ischemia associated with the meningeal process described, were also found.

- MRI of the lumbar spine (Figure 2): presence of fluid build-up with peripheral enhancement shown by the contrast, centered on the upper terminal of the vertebral body of $L 5$, extending to the paravertebral musculature in the left iliopsoas. Presence of three small foci of liquefaction $(2.5 \times 1.3 \mathrm{~cm} ; 3 \times 1.8 \mathrm{~cm} ; 3.1 \times 1.9 \mathrm{~cm})$. A reduction in height of the vertebral body of $L 5$ of more than $50 \%$ is observed. There is a highlighted area in the anterior epidural space, extending from the fourth lumbar vertebra (L4) to the first sacral vertebra (S1), compressing the dural sac and nerve roots of the cauda equina in the fifth lumbar vertebra.

The acid-fast bacilli (AFB) smear was positive in the analysis of sputum samples, and the diagnosis was defined as disseminated tuberculosis (pleural, pulmonary, lymph node, peritoneal, lumbar with psoas abscess and neurotuberculosis). The patient was then started on rifampicin $150 \mathrm{mg}$ (4 pills once a day), isoniazid $75 \mathrm{mg}$ 


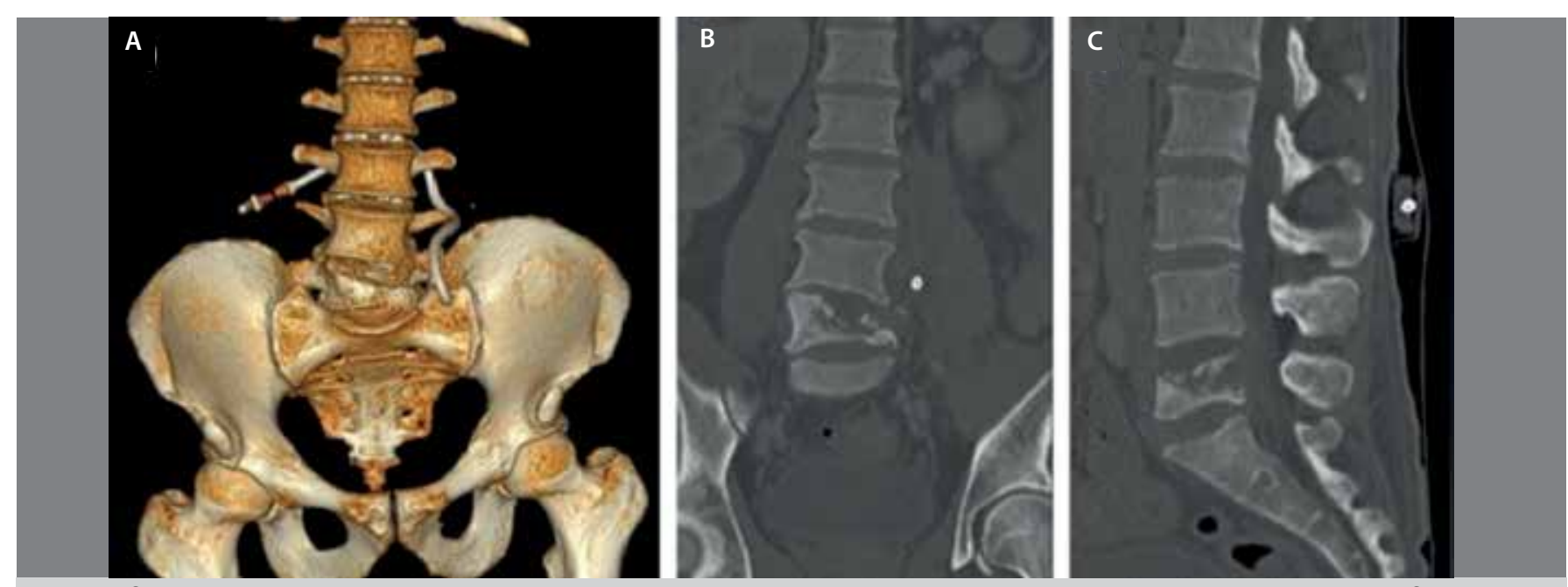

Figure 1. Computed tomography scan of the lumbar spine A) 3D reconstruction with evidence of percutaneous drain; B) coronal cut; C) sagittal cut.
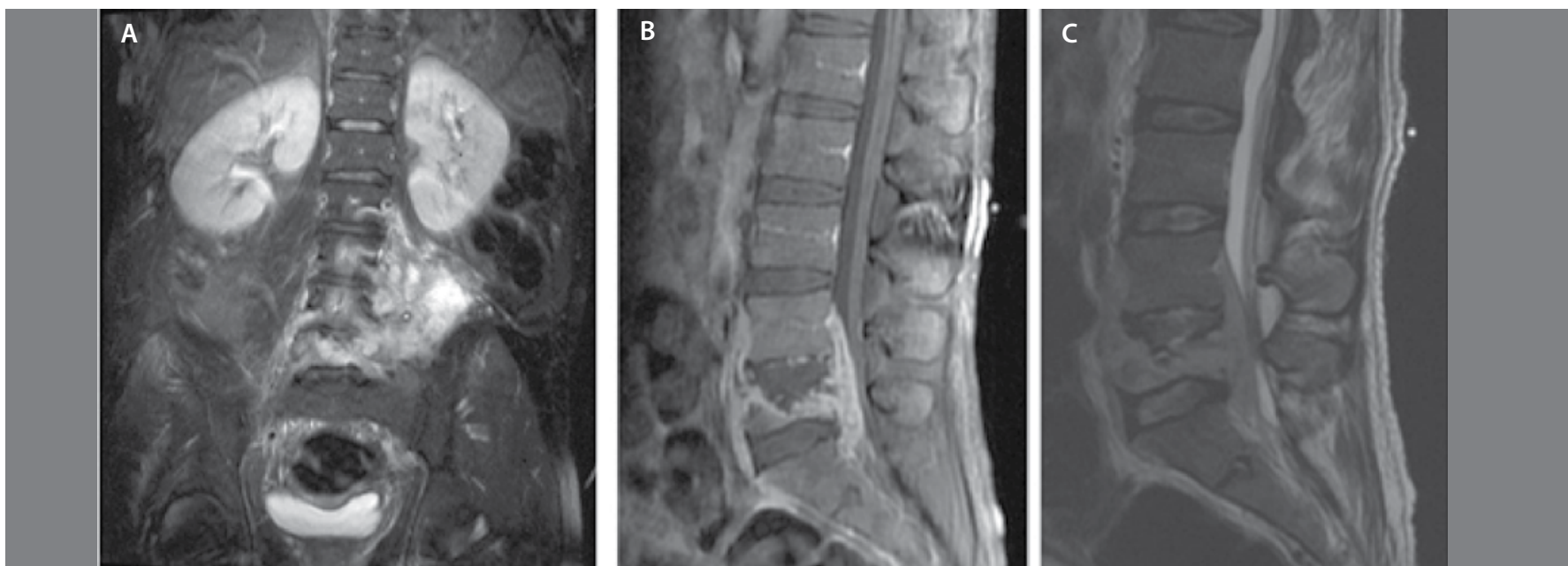

Figure 2. MRI of the lumbar spine (A) coronal cut after injection of contrast; B) sagittal cut after contrast; C) sagittal cut in T2 without contrast.

(4 pills once a day), pyrazinamide $400 \mathrm{mg}$ (4 pills once a day), and ethambutol $275 \mathrm{mg}$ (4 pills once a day).

During hospitalization, the patient was treated by the interventional radiology team, and percutaneous drainage of the left psoas muscle abscess was attempted, through the installation of a $12 \mathrm{~F}$ pigtail Skater catheter. The emergence of a purulent secretion was observed, in which the DNA of Mycobacterium tuberculosis was detected by polymerase chain reaction (PCR), and the acid-fast bacillus was isolated. The patient's symptoms worsened, and a new percutaneous approach was attempted, without success, with worsening of the laboratory and clinical parameters. At that time, it was suggested that the sepsis may be associated with infection of the orifice used for the drainage catheter. Antibiotic therapy was therefore started: vancomycin (2 g attack dose, then 500 mg every $6 \mathrm{~h}$ ) and piperacillin/tazobactam (4 g/500 mg every $6 \mathrm{~h}$ ) for one week. Two weeks after the start of treatment, the patient presented new clinical worsening, with high levels of respiratory discomfort. In light of these new symptoms, chest CT scan was performed, which revealed voluminous pleural effusion in the right lung. Levofloxacin $750 \mathrm{mg}$ 1x/day was empirically introduced, with good evolution for the first 11 days. After that, the patient's general health and mental confusion deteriorated. Meropenem $1 \mathrm{~g} \mathrm{8/8} \mathrm{h} \mathrm{and} \mathrm{vancomycin}$ $1 \mathrm{~g} 8 / 8 \mathrm{~h}$ were introduced. The patient showed good response to treatment, and after four days on the latter antimicrobial regimen, it was decided to change vancomycin for linezolid $600 \mathrm{mg} \mathrm{12/12}$ h. Meropenem + linezolid was maintained for six days, after which the patient underwent surgery to the lumbar spine.

It was decided to perform surgery for the psoas muscle abscess and osteomyelitis of L5. A double route was used, with the anterior extraperitoneal approach, performed by the general surgery team, giving access to the body of $L 5$, which was submitted to subtotal resection along with the discs of L4-L5 and L5-S1 (Figure 3). At this time, new samples of materials were collected for laboratory analysis, decompression of the neural elements was performed, with drainage of the anterior epidural abscess, followed by intense debridement and copious irrigation with saline; a device with hydrostatic distraction was introduced (Aesculap Hydrolift Vertebral Body Replacement, Tuttlingen, Germany), replacing the body of L5 and the discs of L4-L5 and L5-S1. Due to the local infectious process, no type of bone grafting was used. The distraction was applied gradually, with reestablishment of the lumbar lordosis, visualized during the surgery through serial radioscopic imaging (Figure 4). After performing the anterior approach, all the surgical drapes and instruments were changed; the patient was repositioned in the prone position, and posterolateral arthrodesis of $\mathrm{L} 4$ to $\mathrm{S} 1$ was performed via the posterior route, using a bone graft from the iliac crest + instrumentation with pedicle screws that extend from vertebra L4 and S1 bilaterally. 
The material collected during surgery (bone fragment of the body of L5, disc L5, soft tissue, and secretion) was sent for culture. Mycobacterium tuberculosis was detected in the fragment of the disc of $L 5$ and in a fragment of soft tissue. The AFB test was positive for a fragment of soft tissue.

Immediately after surgery, the patient was sent to the intensive care unit, and was discharged to the ward on the following day. Back on the ward, he was encouraged to walk right away, using a walking frame, gradually progressing to walking unaided. On the second postoperative day, control x-ray was performed (Figure 5). On the fourth postoperative day, control CT was performed, showing adequate positioning of the pedicle screws and interbody device (Figure 6). Control MRI was performed on the fifth postoperative day, showing a decrease in the paravertebral fluid collection, and the presence of the interboby device and pedicle screws (Figure 7). The patient presented a satisfactory improvement curve and was discharged after 11 postoperative days, prescribed with rifampicin, isoniazid, pyrazinamide and ethambutol, in the doses mentioned above. Now, four months after surgery, the patient presents very favorable evolution, with full recovery of motor strength in the left leg, and no complaints of pain at rest or walking. He continues to use rifampicin $150 \mathrm{mg}$ (4 tablets once a day) and isoniazid $75 \mathrm{mg}$ (4 tablets once a day), the intention being to complete nine months from the introduction of the medication. Pyrazinamide and ethambutol were suspended after two months from the start of the tuberculosis treatment.

\section{DISCUSSION}

The case presented here is not usual; this is a young patient, without significant comorbidities and without documented immunosuppression, who developed a serious condition of extrapulmonary
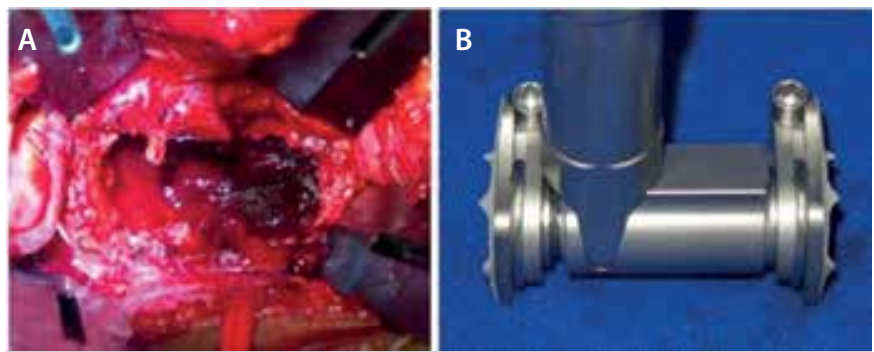

Figure 3. (A) Debridement of the body of L5; B) device with hydrostatic distraction system (Aesculap Hydrolift Vertebral Body Replacement).
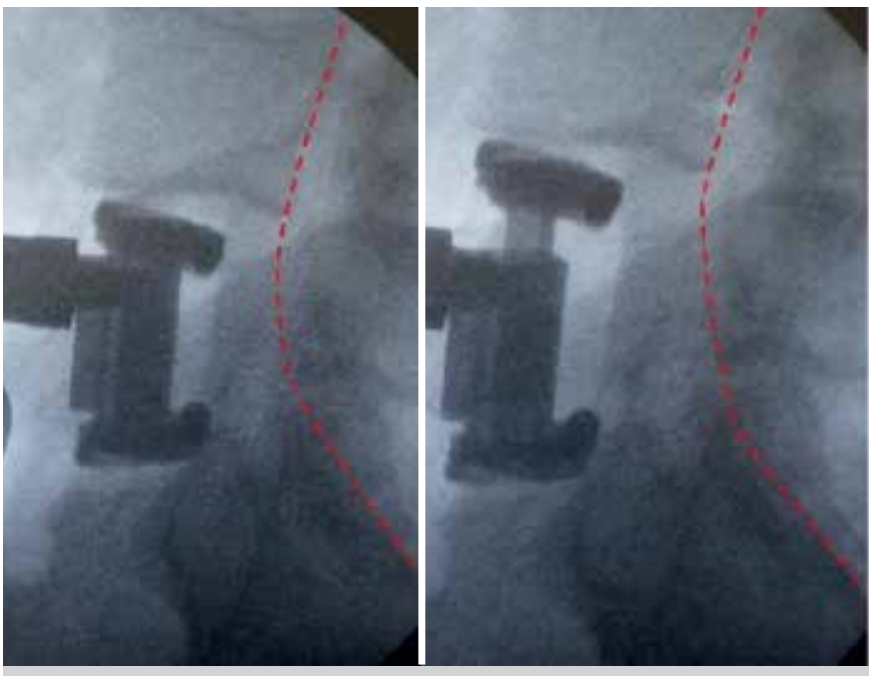

Figure 4. Images of lumbar distraction during surgery. tuberculosis, refractory to initial treatment with antimicrobial chemotherapy. The patient developed disseminated tuberculosis (pleural, pulmonary, lymph node, peritoneal, lumbar, neurotuberculosis) with complication of lumbar tuberculosis, developing an abscess of the psoas muscle. Despite the attempts at percutaneous drainage through interventional radiology, the patient presented disease progression, with worsening of clinical status. The surgical treatment of cases of lumbar tuberculosis complicated by abscess of the psoas muscle is well supported in the medical literature. ${ }^{2,3}$ But there is a great deal of discussion as to which surgery can be used in these cases, from minimally invasive surgery to larger-scale surgery, with double access and extensive debridement. The anterior approach allows the debridement of paravertebral abscesses and reconstruction of the anterior spine, with restoration of sagittal alignment. ${ }^{3}$ Zhang et al. reported a series of 23 patients treated with anterior debridement with structured graft associated with posterior instrumentation, obtaining a good therapeutic response. ${ }^{8}$ The posterior approach alone has some technical advantages that have been discussed by some authors, the main ones being: less surgical time, less bleeding, faster postoperative recovery, and the

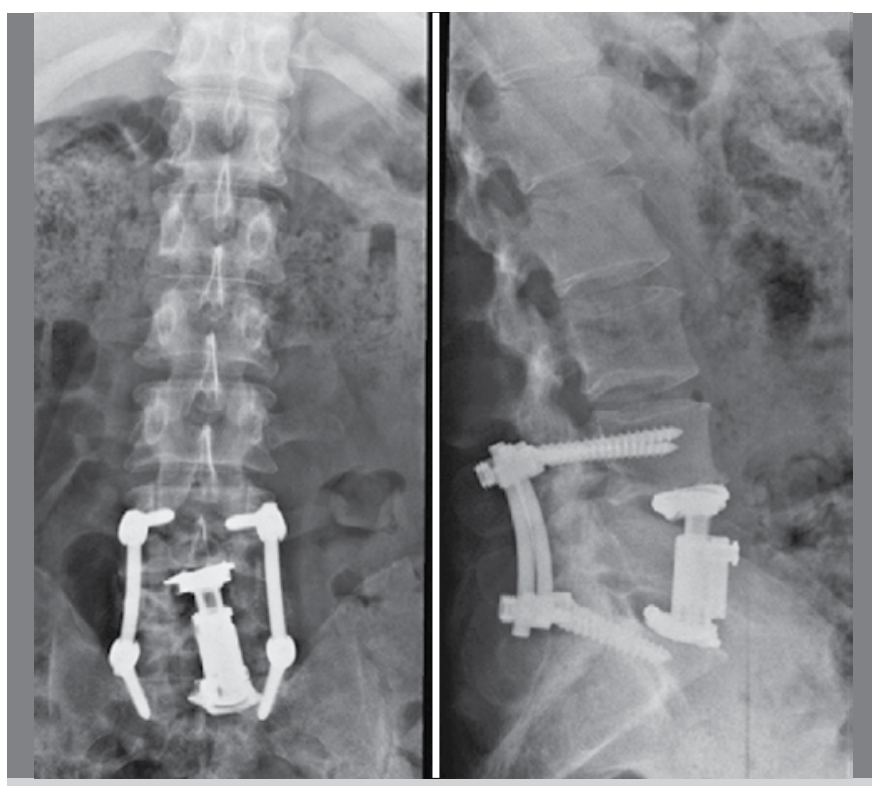

Figure 5. Postoperative control x-rays (anterior-posterior and profile positions).

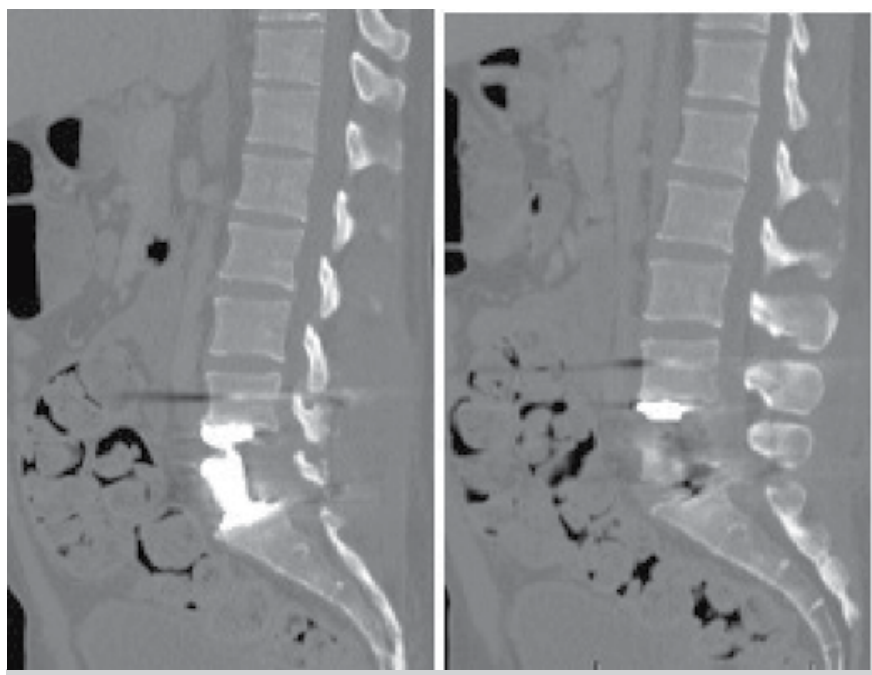

Figure 6. Postoperative control CT scan of the lumbar spine. 

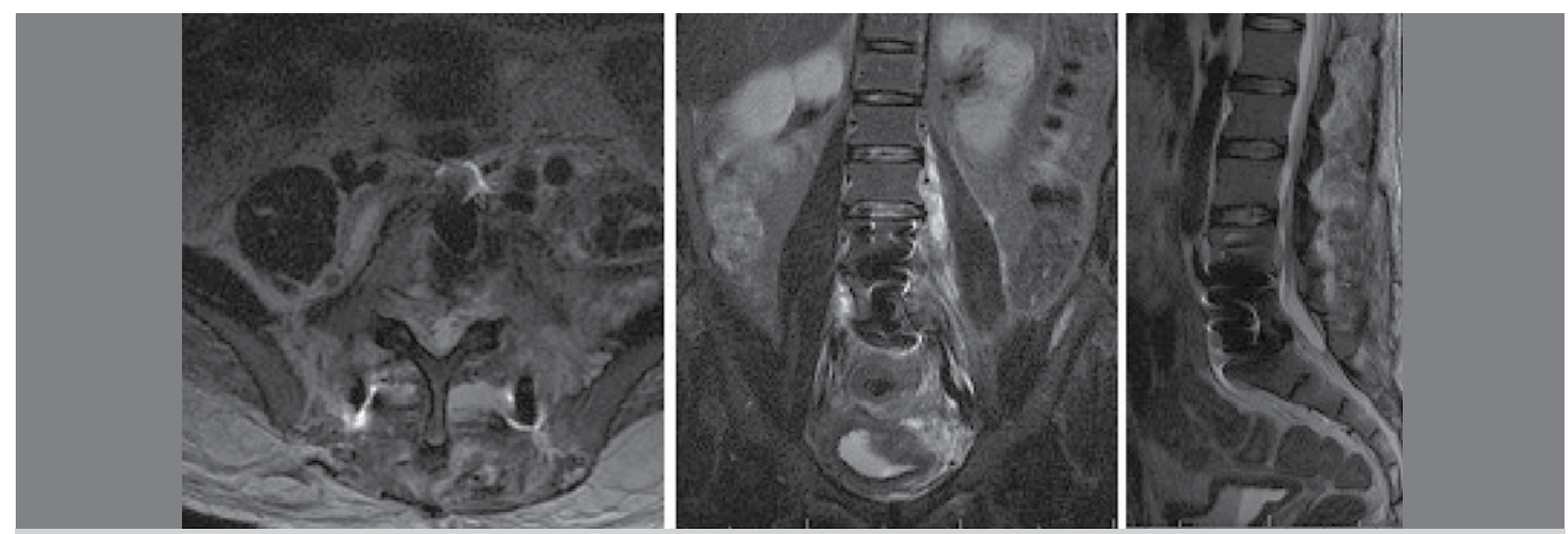

Figure 7. Postoperative control MRI.

fact that a general surgeon is not required. ${ }^{5}$ Tang et al. report a case using the posterior approach alone, in a patient with thoracic involvement who underwent unilateral costotransversectomy. In that case, it was possible to perform anterior decompression, associated with anterior reconstruction with cage, and posterior fixation using pedicle screws. ${ }^{5}$

Posterior access to the vertebral bodies of the lumbar spine is a little more difficult to achieve than in the thoracic spine. Moreover, in cases where lumbar spondylodiscitis is associated with abscess of the paravertebral musculature, the anterior approach allows access to and debridement of the abscess. In the case described, we achieved satisfactory debridement by the anterior route, and reconstruction with a device that enables distraction by a hydrostatic mechanism, enabling control of sagittal alignment, with serial radioscopic imaging during surgery. Posterior fixation, with stimulus to consolidation of the posterolateral arthrodesis with iliac graft, helped to increase the stability of the assembly, allowing early weight-bearing on the first postoperative day, followed by rapid and encouraging recovery on the subsequent days. The patient was discharged 11 days after surgery.

AUTHORS' CONTRIBUTIONS: Each author contributed individually and significantly to the writing of this paper. AOA $(0000-0002-3245-6155)^{\star}$ and TQS $(0000-0003-4581-3243)^{*}$ wrote the paper and performed the surgery; AGT (0000-0002-0436-5168)* and AHAO (0000-0003-2112-4654)* performed the surgery and reviewed the paper; RMM (0000-0001-5958-5646)* and AFC (0000-0002-7797-5274)* reviewed the paper and contributed to the intellectual design of the paper; and TEPBF (0000-0002-7969-7845) ${ }^{\star}$ conceived the entire research project. * ORCID (Open Researcher and Contributor ID).

\section{REFERENCES}

1. Webster AS, Shandera WX. The extrapulmonary dissemination of tuberculosis: A meta-analysis. Int J Mycobacteriol. 2014;3(1):9-16.

2. Carvalho B, Pereira P, Silva PS, Silva J, Pinto M, Vaz R. Espondilodiscite tuberculosa lombar: abordagem cirúrgica minimamente invasiva. Acta Reumatol Port. 2010;35:57-60.

3. Wang X, Pang X, Wu P, Luo C, Shen X. One-stage anterior debridement, bone grafting and posterior instrumentation vs. single posterior debridement, bone grafting, and instrumentation for the treatment of thoracic and lumbar spinal tuberculosis. Eur Spine J. 2014;23(4):830-7.

4. Pang X, Shen X, Wu P, Luo C, Xu Z, Wang X. Thoracolumbar spinal tuberculosis with psoas abscesses treated by one-stage posterior transforaminal lumbar debridement, interbody fusion, posterior instrumentation, and postural drainage. Arch Orthop Trauma Surg. 2013;133(6):765-72.
5. Tang MX, Zhang HQ, Wang YX, Guo CF, Liu JY. Treatment of Spinal Tuberculosis by Debridement, Interbody Fusion and Internal Fixation via Posterior Approach Only. Orthop Surg. 2016;8(1):89-93.

6. Jin W, Wang Q, Wang Z, Geng G. Complete debridement for treatment of thoracolumbar spinal tuberculosis: a clinical curative effect observation. Spine J. 2014;14(6):964-70.

7. Turgut M. Spinal tuberculosis (Pott's disease): its clinical presentation, surgical management, and outcome. A survey study on 694 patients. Neurosurg Rev. $2001 ; 24(1): 8-13$

8. Zhang HQ, Guo CF, Xiao XG, Long WR, Deng ZS, Chen J. One-stage surgical management for multilevel tuberculous spondylitis of the upper thoracic region by anterior decompression, strut autografting, posterior instrumentation, and fusion. J Spinal Disord Tech. 2007;20(4):263-7. 